\title{
The effect of six days of dietary nitrate supplementation on performance in trained CrossFit athletes
}

\author{
Samuel J. Kramer', Daniel A. Baur ${ }^{1}$, Maria T. Spicer ${ }^{1}$, Matthew D. Vukovich² and Michael J. Ormsbee ${ }^{1,3^{*}}$
}

\begin{abstract}
Background: While it is well established that dietary nitrate reduces the metabolic cost of exercise, recent evidence suggests this effect is maintained $24 \mathrm{~h}$ following the final nitrate dose when plasma nitrite levels have returned to baseline. In addition, acute dietary nitrate was recently reported to enhance peak power production. Our purpose was to examine whether chronic dietary nitrate supplementation enhanced peak power $24 \mathrm{~h}$ following the final dose and if this impacted performance in a heavily power-dependent sport.

Methods: In a double-blind, randomized, crossover design, maximal aerobic capacity, body composition, strength, maximal power (30 s Wingate), endurance (2 km rowing time trial), and CrossFit performance (Grace protocol) were assessed before and after six days of supplementation with nitrate (NO) $\left(8 \mathrm{mmol} \cdot\right.$ potassium nitrate $\left.\cdot \mathrm{d}^{-1}\right)$ or a noncaloric placebo (PL). A 10-day washout period divided treatment conditions. Paired $t$-tests were utilized to assess changes over time and to compare changes between treatments.

Results: Peak Wingate power increased significantly over time with NO $(889.17 \pm 179.69 \mathrm{~W}$ to $948.08 \pm 186.80 \mathrm{~W}$; $p=0.01)$ but not PL (898.08 $\pm 183.24 \mathrm{~W}$ to $905.00 \pm 157.23 \mathrm{~W} ; p=0.75)$. However, CrossFit performance was unchanged, and there were no changes in any other performance parameters.

Conclusion: Consuming dietary nitrate in the potassium nitrate salt form improved peak power during a Wingate test, but did not improve elements of strength or endurance in male CrossFit athletes.
\end{abstract}

Keywords: Potassium nitrate, Rowing, Supplementation, Beetroot, Anaerobic power

\section{Background}

Nitric oxide is a signaling molecule which contributes to numerous physiological functions including mitochondrial respiration and biogenesis, vasodilation, muscle glucose uptake, angiogenesis, and sarcoplasmic reticulum calcium handling [1]. As these processes support various physical functions, maximizing nitric oxide production and availability may support exercise performance. Importantly, nitric oxide production can be augmented by ingestion of foods containing nitrate, a precursor for nitrite, which is ultimately reduced to nitric oxide [2].

\footnotetext{
* Correspondence: mormsbee@fsu.edu

${ }^{1}$ Department of Nutrition, Food and Exercise Sciences, Institute of Sports Sciences and Medicine, Florida State University, 1104 Spirit Way, Tallahassee, FL 32306, USA

${ }^{3}$ Discipline of Biokinetics, Exercise, and Leisure Sciences, University of KwaZulu-Natal, Durban, South Africa

Full list of author information is available at the end of the article
}

Elevations in plasma nitrite levels via dietary nitrate have been associated with enhanced endurance capacity and performance [3-8]. These results likely occur via dietary nitrate-mediated reductions in the metabolic cost of exercise. Interestingly, it was recently reported that reductions in the metabolic cost of exercise were evident with chronic nitrate supplementation $\left(6 \mathrm{mmol} \cdot \mathrm{d}^{-1} ; 7-30\right.$ day) $24 \mathrm{~h}$ following the final nitrate dose even though plasma nitrite values had returned to baseline levels [9]. As this may help to guide practical supplementation strategies for athletes, more research is warranted to determine whether this residual effect translates to performance benefits.

In addition, recent research suggests that acute dietary nitrate ingestion augments power production. Coggan et al. [10] reported enhanced isokinetic knee extensor power and calculated velocity $2 \mathrm{~h}$ following ingestion of $140 \mathrm{~mL}$ of beetroot juice $(\sim 11.2 \mathrm{mmol}$ of nitrate) in 
healthy men and women. Similarly, Rimer et al. [11] recently reported that acute (2-3 h preceding exercise) beetroot juice ingestion (140 mL; $\sim 11.2 \mathrm{mmol}$ nitrate) enhanced peak cycling power and pedaling velocity in endurance and power-trained athletes. However, whether chronic nitrate supplementation enhances peak power production is yet to be determined. Moreover, no investigations have assessed whether there is a residual effect of chronic nitrate supplementation on peak power production $\geq 24 \mathrm{~h}$ following the final nitrate dose.

Finally, the impact of dietary nitrate on sportspecific performance among power athletes is yet to be fully determined. CrossFit is a sport that includes a wide variety of generally short-duration, highintensity exercises ranging from Olympic weight lifting to rowing exercises. Performance in this sport is highly dependent on peak power and fatigue resistance [12]. As such, dietary nitrate may be beneficial for CrossFit athletes.

Therefore, our purpose was to investigate the impact of chronic (6 days) nitrate supplementation on laboratorybased and sport-specific performance outcomes among CrossFit athletes $\geq 24 \mathrm{~h}$ following the final nitrate dose. We hypothesized that nitrate supplementation would enhance peak power, $2 \mathrm{~K}$ rowing performance, and CrossFit performance in these athletes.

\section{Methods}

\section{Participants}

Male CrossFit athletes $(N=12)$ aged $20-35$ years were recruited to participate in this study. Characteristics are outlined in Table 1. Participants were not taking any other supplements at the time of the study with the exception fish oil, protein and/or multivitamins. The participants were required to be training in a CrossFit facility $\geq 3$ days' week ${ }^{-1}$ and for $\geq 4$ months. Subjects were encouraged to maintain normal training for the duration of the study ( 40 days).

Table 1 Participant characteristics $(N=12)$

\begin{tabular}{|c|c|}
\hline Variables & Values \\
\hline Age (yr) & $23 \pm 5$ \\
\hline Height (cm) & $175.9 \pm 7.4$ \\
\hline Body Mass (kg) & $82.7 \pm 13.5$ \\
\hline Fat Free Mass (kg) & $70.6 \pm 7.2$ \\
\hline Fat Free Mass (\%) & $86.1 \pm 5.7$ \\
\hline Fat Mass (kg) & $12.1 \pm 7.8$ \\
\hline Fat Mass (\%) & $13.9 \pm 5.7$ \\
\hline $\mathrm{VO}_{2 \text { Peak }}\left(\mathrm{ml} \cdot \mathrm{kg}^{-1} \cdot \mathrm{min}^{-1}\right)$ & $48.5 \pm 7.0$ \\
\hline
\end{tabular}

Values are present mean \pm standard deviation

$V O_{2 \text { Peak }}$, peak oxygen consumption

\section{Research design}

The study design is outlined in Fig. 1. In this randomized, double-blind, crossover study, two treatments were ingested for 6 days: 1) $8 \mathrm{mmol} \cdot \mathrm{d}^{-1}$ potassium nitrate (NO; $2 \times 4 \mathrm{mmol}$ capsules, one consumed in the morning, one in the evening) or 2) $8 \mathrm{mmol} \cdot \mathrm{d}^{-1}$ nitratefree potassium chloride (PL) $(2 \times 4 \mathrm{mmol}$ capsules, one consumed in the morning, one in the evening). Both NO and PL were prepared by the Shaklee Corporation ${ }^{\circ}$. The final nitrate dose was consumed $\geq 24 \mathrm{~h}$ prior to performance testing (see Fig. 1).

Time of day for all testing was kept consistent $( \pm 2 \mathrm{~h})$ for each subject to prevent circadian variation. Participants arrived fasted for at least $3 \mathrm{~h}$ on all testing days. Water was allowed ad libitum. During the tests, no music, encouragement or motivation was provided and participants were prohibited from seeing their results and/or time to complete certain testing procedures, but they were permitted to see how much distance, repetitions, or time remained for respective tests.

During the study period, participants were instructed to follow their normal dietary habits, but were provided with a list of foods high in dietary nitrate and asked to abstain from these foods throughout the duration of the study. Prior to the study, participants filled out a $72 \mathrm{~h}$ food $\log$ ( 2 weekdays, 1 weekend day). A second $72 \mathrm{~h}$ food $\log$ was filled out at the end of the entire study to track any dietary changes. A copy of pre-testing food logs was given back to participants to facilitate the replication of dietary intake patterns each day preceding testing. The participants were asked to avoid strenuous exercise, alcohol, and caffeine $24 \mathrm{~h}$ prior to each testing session. Furthermore, participants were requested to abstain from using antibacterial mouthwash and chewing gum as these are known to negatively impact production of nitric oxide [13]. Participants were also asked to arrive at each testing session adequately hydrated (i.e. without subjective feelings of thirst). Participants were allowed to use exercise aids (excluding chalk) such as tape or wrist wraps for the CrossFit specific "Grace" test, but had to

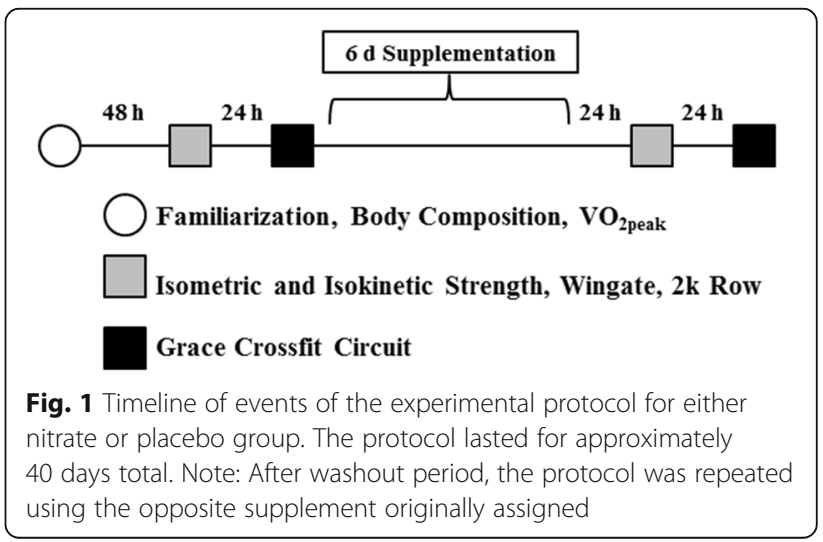


utilize them for all of the trials throughout the study for consistency.

\section{Anthropometrics, body composition, maximal aerobic capacity and familiarization}

Participants visited the laboratory $48 \mathrm{~h}$ prior to baseline performance testing. During this session, height (to the nearest $0.1 \mathrm{~cm}$ ) and weight (to the nearest $0.1 \mathrm{~kg}$ ) were obtained with the use of a wall-mounted SECA 216 stadiometer (SECA ${ }^{\circ}$, Hamburg, Germany) and a digital scale (Detecto ${ }^{\circ} 750$, Webb City, MO). Then, body composition was determined using air displacement plethysmography with thoracic volume being estimated (BodPod ${ }^{\circ}$, Cosmed USA Inc., Chicago, IL). Percent body fat was estimated via the Siri equation [14]. Thoracic volume was estimated based on reference data in healthy adults [15]. These measurements were taken without shoes, and wearing only compression shorts. Finally, a peak oxygen consumption ( $\left.\mathrm{VO} 2_{\text {peak }}\right)$ test on a motor driven treadmill (Woodway", Waukesha, WI, USA) was performed with a calibrated metabolic cart (TrueOne 2400, Parvo Medics, Inc., Sandy, UT, USA). The speed of the treadmill was set at $9.66 \mathrm{~km} \cdot \mathrm{h}^{-1}$ at $0 \%$ grade. The grade was then increased by $2 \% \cdot \mathrm{min}^{-1}$ until volitional exhaustion. The sign for volitional exhaustion was when the participants could no longer keep pace with the treadmill belt, and/or they indicated to the researcher with a "thumbs down" hand signal that they desired to stop the test. After this preliminary testing, participants were familiarized with all procedures on one occasion by completing all testing protocols without data being collected.

\section{Visit 1}

After arrival at the laboratory, isokinetic and isometric extension and flexion strength testing was performed on a dynamometer (Biodex System 3, Biodex Medical Systems, Inc., Shirley, New York). The participants were seated with their dominant leg strapped to the lever arm at a $90^{\circ}$. To further secure participants, a lap belt and two crossing shoulder belts over the chest were affixed. The participants were asked to cross their arms and keep their hands flat against the chest belts so as not to induce isopressor increases in blood pressure or alter leverage to enhance force production. On the dynamometer, the isokinetic quadriceps extension and hamstring flexion contractions consisted of $2 \times 5$ repetitions at both $60^{\circ} \cdot \mathrm{s}^{-1}$ and $180^{\circ} \cdot \mathrm{s}^{-1}$ with $1 \mathrm{~min}$ rest between each set. The isometric contractions consisted of $2 \times 5$ quadriceps extension and hamstring flexion repetitions and were performed at $60^{\circ}$ of knee flexion with $5 \mathrm{~s}$ rest between repetitions and 1 min rest between sets. Subjects were not provided verbal encouragement or performance feedback.
After 10 min of passive rest, maximal power and fatigability was measured via a $30 \mathrm{~s}$ Wingate test on a Velotron cycle ergometer (RacerMate, Inc., Seattle, WA). Testing procedures have been described elsewhere [16]. The participants were asked to remain seated during the test.

After a 15-min passive rest in which the participants could drink water ad libitum, participants mounted a rowing ergometer (Concept2 ${ }^{\circ}$ Model D, Concept2, Inc., Morrisville, VT), and their feet were strapped down via Velcro straps. Participants then completed a $3 \mathrm{~min}$ warm-up consisting of 10 subjectively "hard" strokes at the start of each min. Thereafter, a $2 \mathrm{~K}$ time trial was completed as quickly as possible at a resistance level of $3-5$. During the warm-up and time trial, participants were monitored to ensure adequate form. A good stroke consisted of the body progressing forward up the slide as far as possible and then driving back with the legs, back and arms, in that order, at the top of each stroke. Relative time was calculated from a weight-adjustment factor provided by the ergometer manufacturer:

$$
[\text { body mass in pounds } / 270]^{0.222} \times \text { raw time }(s)
$$

\section{Visit 2}

The next day, the CrossFit workout known as "Grace" was performed. The Grace is a common benchmark workout in CrossFit used to track performance improvements. This performance test was chosen due to its simplicity relative to other CrossFit benchmarks (i.e. one movement and one apparatus), and because of its heavy dependence on power development and endurance. As it is commonly featured in CrossFit competitions, the Grace was taken to be a valid assessment of CrossFit performance. For the Grace performance test, each participant was instructed to complete 30 clean-and-jerk repetitions using $61.37 \mathrm{~kg}$ as fast as possible. The total time to complete all 30 repetitions was recorded and used for data analysis on each trial. The participants were allowed to warm up with the bar by itself and with weights if desired, with a limit of $61.37 \mathrm{~kg}$. A complete repetition included the elbows being locked out when the bar came above the head and plates touching the ground when bringing the bar downwards for the next repetition.

\section{Supplementation protocol}

Participants consumed their assigned supplement for 6 days (beginning the evening following Visit 2 testing). The participants took one pill in the evening, 30-60 min before bed each night and another pill 30-60 min before they ate their first meal of the day each morning. The supplement protocol was similar to previous research $[17,18]$ that tested the effects of dietary nitrate supplementation for 15 days and reported increases in blood 
nitrate following supplementation. Empty supplement bottles were returned to the research staff to verify compliance after 6 days of supplementation. During the supplementation period, the participants were only allowed to exercise for the first 4 days, but could not exercise at all on days 5 and 6 . Compliance was confirmed with a training $\log$ and by a weekly mid-point phone call to remind participants of the supplementation and training instructions. After the 6 days supplementation period, participants returned to the laboratory for post-testing (Visit 3 and 4). Following a 10 day washout period (common among similar studies $[5,6])$, participants were assigned the opposite treatment that they took for the first 6 days, and repeated the same procedures described above.

\section{Dietary analysis}

All pre-test and post-test dietary food logs were analyzed by the same researcher using The Food Processor software (ESHA Research ${ }^{\circ}$, V.10.11, Salem, OR).

\section{Statistical analysis}

Treatment order was randomized using an internet-based application (Random Sequence Generator, www.random.org). Changes from pre- to post-treatment were examined via a paired $t$-test. Additionally, change scores $(\Delta)$ were calculated and compared via paired student's $t$-test. All analyses were completed on SPSS version 22 (IBM Corp., Armonk, $\mathrm{NY})$. Values were presented as mean $\pm \mathrm{SD}$.

\section{Results}

\section{Strength, power, and endurance testing}

Strength, power, and endurance testing results are presented in Table 2. There were no differences from preto post-treatment nor between $\Delta$ for any strength, power, or endurance variable with one exception. For the 30-s Wingate, there was a significant increase in peak power following supplementation with $\mathrm{NO}(p=$ 0.01; Fig. 2). Moreover, there was a strong trend for a larger $\Delta$ with NO relative to PL $(p=0.08)$.

\section{CrossFit performance}

Results are outlined in Table 2. There were no changes in CrossFit performance.

\section{Adverse effects}

Adverse events were reported for both $\mathrm{NO}(n=5)$ and PL $(n=3)$. Slight nausea and gastrointestinal discomfort were reported with morning supplement consumption in NO, but these subsided once food was consumed. Similarly, slight gastrointestinal discomfort was reported with morning supplement consumption in PL, but these subsided once food was consumed.

\section{Discussion}

Previous research has established that dietary nitrate reduces the metabolic cost of exercise, and this effect is maintained $24 \mathrm{~h}$ following the final dose of a nitrate supplementation regimen [9]. Additionally, nitrate supplementation has been reported to enhance peak power output $[10,11]$. However, whether this ergogenic effect is also present following $24 \mathrm{~h}$ following nitrate ingestion, or if this ergogenic effect translates to performance improvements in sport-specific tasks dependent on power has not been determined. The primary finding of the current study was that 6 days of potassium nitrate supplementation enhanced peak power output in a Wingate cycling test among trained CrossFit athletes when assessed $24 \mathrm{~h}$ following the final nitrate dose. However,

Table 2 Effects of nitrate supplementation on performance among CrossFit athletes

\begin{tabular}{|c|c|c|c|c|c|c|}
\hline \multirow[t]{2}{*}{ Performance Test } & \multicolumn{3}{|l|}{$\mathrm{PL}$} & \multicolumn{3}{|l|}{$\mathrm{NO}$} \\
\hline & Pre & Post & $\Delta(\%)$ & Pre & Post & $\Delta(\%)$ \\
\hline Grace Test (s) & $281.75 \pm 41.84$ & $270.92 \pm 129.16$ & $-3.84 \pm 8.94$ & $295.92 \pm 170.98$ & $263.67 \pm 117.74$ & $-8.94 \pm 31.14$ \\
\hline Isometric Ext.60 $(N)$ & $174.15 \pm 27.59$ & $184.80 \pm 43.41$ & $6.11 \pm 17.36$ & $169.06 \pm 36.63$ & $186.29 \pm 48.67$ & $10.19 \pm 36.60$ \\
\hline Isometric Flex. $60^{\circ}(\mathrm{N})$ & $119.83 \pm 16.62$ & $125.53 \pm 19.66$ & $4.76 \pm 18.29$ & $116.82 \pm 21.35$ & $118.95 \pm 26.51$ & $1.82 \pm 24.17$ \\
\hline Isokinetic Ext. $60^{\circ} \cdot \mathrm{s}^{-1}(\mathrm{~N})$ & $184.07 \pm 48.53$ & $179.31 \pm 44.09$ & $-2.59 \pm 9.15$ & $174.61 \pm 41.03$ & $167.76 \pm 50.14$ & $-3.92 \pm 22.20$ \\
\hline Isokinetic Flex. $60^{\circ} \cdot \mathrm{s}^{-1}(\mathrm{~N})$ & $106.40 \pm 24.54$ & $103.59 \pm 25.12$ & $-2.64 \pm 2.36$ & $103.73 \pm 21.32$ & $102.19 \pm 26.41$ & $-1.48 \pm 23.87$ \\
\hline Isokinetic Ext. $180^{\circ} \cdot \mathrm{s}^{-1}(\mathrm{~N})$ & $120.14 \pm 42.32$ & $123.28 \pm 35.31$ & $2.68 \pm 16.56$ & $120.33 \pm 35.98$ & $128.21 \pm 31.95$ & $6.55 \pm 11.20$ \\
\hline Isokinetic Flex. $180^{\circ} \cdot \mathrm{s}^{-1}(N)$ & $75.65 \pm 27.59$ & $76.23 \pm 20.43$ & $0.77 \pm 25.95$ & $79.35 \pm 14.17$ & $79.68 \pm 16.00$ & $0.42 \pm 12.91$ \\
\hline Wingate Peak (W) & $898.08 \pm 183.24$ & $905.00 \pm 157.23$ & $0.77 \pm 14.19$ & $889.17 \pm 179.69$ & $948.08 \pm 186.80^{\mathrm{a}}$ & $6.62 \pm 3.96$ \\
\hline Wingate Mean (W) & $703.08 \pm 101.66$ & $736.08 \pm 95.31$ & $4.69 \pm 6.25$ & $724.17 \pm 109.93$ & $737.58 \pm 118.93$ & $1.85 \pm 8.19$ \\
\hline $2 \mathrm{~K} \pi(\mathrm{s})$ & $465.07 \pm 28.45$ & $459.87 \pm 24.85$ & $-1.12 \pm 12.65$ & $457.57 \pm 23.56$ & $459.73 \pm 23.93$ & $0.47 \pm 1.57$ \\
\hline $2 \mathrm{~K} \Pi\left(\mathrm{s} \cdot \mathrm{kg}^{-1}\right)$ & $392.43 \pm 79.51$ & $387.26 \pm 71.09$ & $-1.31 \pm 10.59$ & $384.78 \pm 66.59$ & $387.40 \pm 72.44$ & $0.68 \pm 8.78$ \\
\hline
\end{tabular}

Values are present mean \pm standard deviation; PL placebo, NO nitrate, $s$ seconds, $W$ watts, $N$ newtons, $T$ time trial, Ext. extension; Flex. Flexion. Grace is defined as 30 clean-and-jerks, and performance is defined as time to complete all repetitions. All isometric and isokinetic tests evaluate peak torque

${ }^{a}$ indicates increase from pre- to post-supplementation as determined via paired $t$-test, $p=0.01$ 


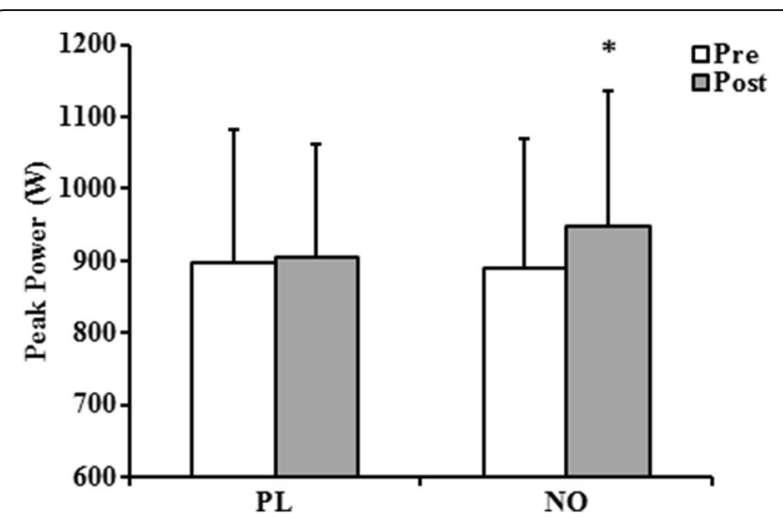

Fig. 2 Changes in peak power during a Wingate test pre to post 6 day of placebo or nitrate supplementation. PL, placebo; NO, nitrate. Data are presented as mean \pm standard deviation. ${ }^{*}$ denotes an increase in peak power relative to pre-treatment $(p=0.01)$

there were no improvements in any other performance outcome including time to complete a Grace CrossFit workout.

In the current study, nitrate supplementation enhanced peak power production. This is the first study to report enhanced peak power as a result of chronic dietary nitrate supplementation $24 \mathrm{~h}$ following the final nitrate dose. Prior studies have reported enhanced peak power following acute nitrate supplementation [10, 11]. Specifically, Coggan et al. [10] reported enhanced isokinetic knee extensor power among healthy men and women $2 \mathrm{~h}$ following $140 \mathrm{~mL}(\sim 11.2 \mathrm{mmol}$ nitrate) of beetroot juice. Additionally, Rimer et al. [11] reported enhanced peak power in a Wingate test among endurance and power-trained athletes following the same $140 \mathrm{~mL}$ beetroot juice dose. There are a number of possible mechanisms for enhanced Wingate peak power with chronic nitrate supplementation (discussed below).

A novel finding of the current study was that the effects of chronic nitrate supplementation on peak power were maintained $\geq 24 \mathrm{~h}$ following the final nitrate dose. Wylie et al. [9] recently found that $\sim 28$ days nitrate supplementation $\left(6 \mathrm{mmol} \cdot \mathrm{d}^{-1}\right)$ reduced the metabolic cost of exercise $24 \mathrm{~h}$ following the final nitrate dose despite plasma nitrite levels returning to baseline. Our data suggests that chronic nitrate-mediated effects on peak power are similarly maintained $24 \mathrm{~h}$ following the final nitrate dose. Prior research has indicated that nitrate supplementation causes increased production of mouse skeletal muscle structural proteins involved in calcium handling [19]. These changes may be maintained for a period of time following the reduction in plasma nitrite post-supplementation. Additionally, skeletal muscle and/ or other tissues may act as a reservoir for nitric oxide precursors like nitrate and nitrite, and storage of these products may be maintained $\geq 24 \mathrm{~h}$ [20]. Interestingly, these "residual" changes in peak Wingate power $24 \mathrm{~h}$ following the final nitrate dose were apparent following only 6 days of nitrate supplementation. In contrast, Wylie et al. [9] did not report changes in the metabolic cost of exercise following 7 days of supplementation, but did see a reduction following $\sim 28$ days. It is possible that structural changes which influence peak power are unique from those that impact the metabolic cost of exercise and are more sensitive to nitrate supplementation. However, more research is warranted to elucidate these mechanisms.

There were no changes in peak torque during isokinetic testing. This finding is in contrast to a prior study [10]. Coggan et al. [10] assessed isokinetic knee extensor torque at $0^{\circ} \cdot \mathrm{s}^{-1}, 90^{\circ} \cdot \mathrm{s}^{-1}, 180^{\circ} \cdot \mathrm{s}^{-1}, 270^{\circ} \cdot \mathrm{s}^{-1}$, and $360^{\circ} \cdot \mathrm{s}^{-1}$. It is possible that we failed to detect any changes in isokinetic peak torque due to the velocities utilized in the current study $\left(60^{\circ} \cdot \mathrm{s}^{-1}\right.$ and $\left.180^{\circ} \cdot \mathrm{s}^{-1}\right)$. In the study by Coggan et al. [10], power was significantly enhanced at $360^{\circ} \cdot \mathrm{s}^{-1}$, but at no other velocities. This data suggests that the impact of nitrate on peak torque may only apparent at high velocities, which may explain why we failed to note any differences for isokinetic knee extensor torque in the current study. Prior research in animals suggests that nitrate supplementation may augment maximal shortening velocity in fast-twitch muscle fibers, but have relatively little impact on slow-twitch fibers [21, 22]. If this is also the case in humans, it makes sense that peak power in a Wingate test, but not isokinetic power at $60^{\circ} \cdot \mathrm{s}^{-1}$ and $180^{\circ} \cdot \mathrm{s}^{-1}$, would be enhanced following nitrate supplementation as this exercise is likely highly reliant on fast-twitch fibers [23].

Despite enhancements in peak power output in the Wingate test, performance in a $2 \mathrm{~km}$ rowing time trial was unchanged. This contrasts with recent research investigating the effects of nitrate on high-intensity exercise capacity. For instance, a number of studies have reported enhanced performance in short-duration ( $\sim 6 \mathrm{~min})$, highintensity time trials $[4,24]$, endurance capacity in exercise lasting $\sim 5-12 \mathrm{~min}[5,8]$ and performance in highintensity intermittent running [25]. Worth noting, two recent studies have reported enhanced performance among well-trained rowers following acute or chronic nitrate supplementation [24, 26]. Hoon et al. [24] found $2 \mathrm{~K}$ rowing performance to be possibly enhanced with $140 \mathrm{~mL}$ of beetroot juice $(8.4 \mathrm{mmol}$ nitrate) $2 \mathrm{~h}$ prior to exercise. Moreover, Bond et al. [26] reported enhancements in time to complete 6 repeated $500 \mathrm{~m}$ rowing bouts following 6 days of beetroot juice supplementation $(5.5 \mathrm{mmol}$ nitrate $\mathrm{d}^{-1}$ ) in well-trained junior rowers. Based on these studies, our finding of no change in time trial performance is somewhat surprising, particularly considering that our subjects were familiarized, and the exercise protocol seemed to be highly reliable $(<1.5 \% \mathrm{CV})$ even for athletes who were less-accustomed to rowing exercise. It is 
possible that the $24 \mathrm{~h}$ delay between the final nitrate dose and the time trial influenced our findings despite the aforementioned prior study [9] reporting that nitratemediated improvements in exercise efficiency are maintained within this timeframe. Another possibility is that the form of nitrates consumed influenced performance effects. Indeed, a recent study [27] showed that the oxygen cost of exercise was reduced with pre-exercise beetroot juice, but not nitrate salt, ingestion.

Performance was also unchanged in the Grace CrossFit protocol. One other study has investigated CrossFit specific workouts following supplementation (6 weeks) with a product that contains nitrate (beetroot extract) [16]. In this study, two CrossFit workouts were assessed for changes from pre- to post-supplementation: 1) a 500-m row, 40 wall balls, 30 push-ups, 20 box jumps, and 10 thrusters, and 2) $800 \mathrm{~m}$ run followed by as many rounds as possible of 5 burpees, 10 Kettlebell swings, and 15 air squats within $15 \mathrm{~min}$. Similar to our results, supplementation did not provide a statistically significant difference in terms of improvement for the first CrossFit workout. However, in agreement with this prior study, we found large magnitude relative changes in time to complete the workouts with $\mathrm{NO}$ vs. PL $(-8.94 \% \pm$ $31.14 \%$ vs. $-3.84 \pm 8.94 \%$ ), which were suggestive of benefits. Of note, the prior study [16] did report a likely increase in repetitions completed in the second workout suggesting that supplementation with products containing nitrate benefit CrossFit performance; however, this is somewhat speculative as beetroot extract was only one of a number of other ingredients contained in the supplement utilized. Taken together, our results combined with this prior study indicate potential benefits of nitrate on CrossFit performance, but future research is warranted to determine more reliable methods of assessing performance changes in this sport.

A number of instances of gastrointestinal distress were reported with nitrate supplementation in the current study. This may have been a consequence of the nitrate form utilized (i.e. nitrate salt). Indeed, gastrointestinal symptoms have been reported in a prior study utilizing nitrate salts [28]. As such, it may be advisable for athletes to consume nitrate in whole food forms such as beetroot juice particularly in light of the recent evidence suggesting this has a greater impact on the metabolic cost of exercise versus nitrate salts [27].

This study had several limitations. First, CrossFit performance testing was conducted $\sim 48 \mathrm{~h}$ following the final dose of supplement in an effort to avoid the influence of gastrointestinal distress on performance. As such, this may have attenuated any nitrate-mediated performance benefits. In addition, performance results with the CrossFit protocol utilized in the current study were highly variable. The Grace protocol requires all participants to lift the same amount of weight $(61.4 \mathrm{~kg})$ despite sometimes drastic differences in body mass and strength. As a result, time to complete the Grace protocol varied considerably between participants. Moreover, in participants who were particularly challenged by the weight, withinsubject variation was also high due to failed lifts. Thus, while the Grace is a common benchmark workout in CrossFit, it may lack sensitivity for small, but meaningful changes. Lastly, participants in the study only completed one familiarization session of the all the exercise protocols. As such, it is possible that learning effects were present, particularly with isokinetic strength testing [29]. However, studies specifically examining the reproducibility of Biodex isokinetic strength over multiple sessions have found no evidence of a learning effect [30, 31]. Thus, we are confident that our familiarization was sufficient to prevent learning effects.

\section{Conclusion}

In conclusion, 6 days of dietary nitrate supplementation in male CrossFit athletes improved peak Wingate power $24 \mathrm{~h}$ following the final nitrate dose. However, there were no improvements in rowing time- trial or CrossFit performance. Future research is warranted to elucidate mechanisms responsible for changes in peak power output, improve methods for assessing CrossFit performance, and further investigate whether nitrate supplementation enhances performance in strength and power-based sports.

\section{Abbreviations}

2K: 2000-meter rowing test; ADP: Adenosine diphosphate; BRJ: Beetroot juice; eNOS: Endogenous nitric oxide synthase; N: Newtons; NO: Potassium nitrate; PCr: Phosphocreatine; PL: Placebo

\section{Acknowledgments}

The authors would also like to thank Sean and Rachel Dodrill from CrossFit Blackbox in Tallahassee, FL and Daniel Rivas, Christopher Bach, Karly Rudy, Bailey Koch, Rachel Drummey, and Palmer Johnson for assistance with data collection.

\section{Funding}

The authors would like to especially thank Shaklee Corporation ${ }^{\circledR}$ for their product donation as well as funding to support this project.

\section{Availability of data and materials}

The dataset supporting the conclusions of this article is not available as it will be used for subsequent analyses.

\section{Authors' contributions}

MJO and SJK conceived of the study, carried out data collection and developed the draft of manuscript. DAB performed data analysis and statistics and contributed to drafting the manuscript, MTS, and MDV assisted with study design and statistical analysis. All other authors read and reviewed the final manuscript. All authors read and approved the final manuscript.

Competing interests

The authors declare they have no competing interests.

Consent for publication

Not applicable. 


\section{Ethics approval and consent to participate}

The participants were notified of all of the potential risks and benefits associated with the study before written informed consent was obtained. This study was approved by the Florida State University Institutional Review Board and written and verbal consent was obtained prior to commencement of the study.

\section{Author details}

'Department of Nutrition, Food and Exercise Sciences, Institute of Sports Sciences and Medicine, Florida State University, 1104 Spirit Way, Tallahassee, FL 32306, USA. ${ }^{2}$ Department of Health \& Nutritional Sciences, South Dakota State University, Brookings, SD, USA. ${ }^{3}$ Discipline of Biokinetics, Exercise, and Leisure Sciences, University of KwaZulu-Natal, Durban, South Africa.

Received: 25 May 2016 Accepted: 25 October 2016 Published online: 03 November 2016

\section{References}

1. Jones AM. Dietary nitrate supplementation ank fd exercise performance. Sport Med. 2014:44:35-45.

2. Lundberg JO, Gladwin MT, Ahluwalia A, Benjamin N, Bryan NS, Butler A, et al. Nitrate and nitrite in biology, nutrition and therapeutics. Nat Chem Biol. 2009;5:865-9.

3. Cermak NM, Gibala MJ, Van Loon LJC. Nitrate supplementation's improvement of 10-km time-trial performance in trained cyclists. Int J Sport Nutr Exerc Metab. 2012;22:64-71

4. Lansley KE, Winyard PG, Bailey SJ, Vanhatalo A, Wilkerson DP, Blackwell JR, et al. Acute dietary nitrate supplementation improves cycling time trial performance. Med Sci Sport Exerc. 2011;43:1125-31.

5. Bailey SJ, Winyard P, Vanhatalo A, Blackwell JR, Dimenna FJ, Wilkerson DP, et al. Dietary nitrate supplementation reduces the $\mathrm{O} 2$ cost of low-intensity exercise and enhances tolerance to high-intensity exercise in humans. J Appl Physiol. 2009:107:1144-55.

6. Bailey SJ, Fulford J, Vanhatalo A, Winyard PG, Blackwell JR, DiMenna FJ, et al. Dietary nitrate supplementation enhances muscle contractile efficiency during knee-extensor exercise in humans. J Appl Physiol. 2010;109:135-48.

7. Larsen FJ, Weitzberg E, Lundberg JO, Ekblom B. Dietary nitrate reduces maximal oxygen consumption while maintaining work performance in maximal exercise. Free Rad Bio Med. 2010:48:342-7.

8. Kelly J, Vanhatalo A, Wilkerson DP, Wylie LJ, Jones AM. Effects of nitrate on the power-duration relationship for severe-intensity exercise. Med Sci Sport Exerc. 2013;45:1798-806

9. Wylie L, Ortiz de Zevallos J, Isidore T, Nyman L, Vanhatalo A, Bailey SJ, et al. Dose-dependent effects of dietary nitrate on the oxygen cost of moderateintensity exercise: Acute vs. chronic supplementation. Nitric Oxide. 2016;57:30-9.

10. Coggan AR, Leibowitz JL, Kadkhodayan A, Thomas DP, Ramamurthy S, Spearie CA, et al. Effect of acute dietary nitrate intake on maximal knee extensor speed and power in healthy men and women. Nitric Oxide. 2015; 48:16-21.

11. Rimer EG, Peterson LR, Coggan AR, Martin JC. Acute Dietary Nitrate Supplementation Increases Maximal Cycling Power in Athletes. Int J Sport Physiol Perform. 2015:11(6):715-20.

12. Bellar D, Hatchett A, Judge LW, Breaux ME, Marcus L. The relationship of aerobic capacity, anaerobic peak power and experience to performance in CrossFit exercise. Biol Sport. 2015;32:315-20.

13. Govoni $M_{1}$ Jansson EA, Weitzberg E, Lundberg JO. The increase in plasma nitrite after a dietary nitrate load is markedly attenuated by an antibacterial mouthwash. Nitric Oxide. 2008;19:333-7.

14. Siri WE. Body composition from fluid spaces and density: analysis of methods. In: Brozek J, Henschel A, editors. Tech. Meas. body Compos. Washington: Natl Acad Sciences/Natl Res Council; 1961. p. 223-4.

15. Crapo RO, Morris AH, Clayton PD, Nixon CR. Lung volumes in healthy nonsmoking adults. Bull Eur Physiopath Respir. 1982;18:419-25.

16. Outlaw JJ, Wilborn CD, Smith-Ryan AE, Hayward SE, Urbina SL, Taylor LW, et al. Effects of a pre-and post-workout protein-carbohydrate supplement in trained crossfit individuals. Springerplus. 2014;3:369.

17. Fulford J, Winyard PG, Vanhatalo A, Bailey SJ, Blackwell JR, Jones AM. Influence of dietary nitrate supplementation on human skeletal muscle metabolism and force production during maximum voluntary contractions. Pflugers Arch. 2013;465:517-28.
18. Vanhatalo A, Bailey SJ, Blackwell JR, DiMenna FJ, Pavey TG, Wilkerson DP, et al. Acute and chronic effects of dietary nitrate supplementation on blood pressure and the physiological responses to moderate-intensity and incremental exercise. Am J Physiol Reg Integr Comp Physiol. 2010;299:R1121-31.

19. Hernández A, Schiffer TA, Ivarsson N, Cheng AJ, Bruton JD, Lundberg JO, et al. Dietary nitrate increases tetanic [Ca2+]i and contractile force in mouse fast-twitch muscle. J Physiol. 2012;590:3575-83.

20. Piknova B, Park JW, Swanson KM, Dey S, Noguchi CT, Schechter AN. Skeletal muscle as an endogenous nitrate reservoir. Nitric Oxide. 2015;47:10-6.

21. Ferguson SK, Hirai DM, Copp SW, Holdsworth CT, Allen JD, Jones AM, et al. Impact of dietary nitrate supplementation via beetroot juice on exercising muscle vascular control in rats. J Physiol. 2013;591:547-57.

22. Maréchal G, Beckers-Bleukx G. Effect of nitric oxide on the maximal velocity of shortening of a mouse skeletal muscle. Pflugers Arch. 1998;436:906-13.

23. Coyle EF, Costill DL, Lesmes GR. Leg extension power and muscle fiber composition. Med Sci Sport. 1979;11:12-5.

24. Hoon MW, Jones AM, Johnson NA, Blackwell JR, Broad EM, Lundy B, et al. The effect of variable doses of inorganic nitrate-rich beetroot juice on simulated 2000-m rowing performance in trained athletes. Int J Sport Physiol Per. 2014;9:615-20.

25. Wylie LJ, Mohr M, Krustrup P, Jackman SR, Ermdis G, Kelly J, et al. Dietary nitrate supplementation improves team sport-specific intense intermittent exercise performance. Eur J Appl Physiol. 2013;113:1673-84.

26. Bond $H$, Morton $L$, Braakhuis AJ. Dietary nitrate supplementation improves rowing performance in well-trained rowers. Int J Sport Nutr Exerc Metab. 2012;22:251-6.

27. Flueck JL, Bogdanova A, Mettler S, Perret C. Is beetroot juice more effective than sodium nitrate? The effects of equimolar nitrate dosages of nitrate-rich beetroot juice and sodium nitrate on oxygen consumption during exercise. Appl Physiol Nutr Metab. 2016;41:421-9.

28. Peacock O, Tjønna AE, James P, Wisløff U, Welde B, Böhlke N, et al. Dietary nitrate does not enhance running performance in elite cross-country skiers. Med Sci Sport Exerc. 2012:44:2213-9. Available from: http://www.ncbi.nlm. nih.gov/pubmed/22874535.

29. Dirnberger J, Wiesinger H-P, Kösters A, Müller E. Reproducibility for isometric and isokinetic maximum knee flexion and extension measurements using the IsoMed 2000-dynamometer. Isokin Ex Sci. 2012;20:149-53. IOS Press.

30. Lund H, Søndergaard K, Zachariassen T, Christensen R, Bülow P, Henriksen $M$, et al. Learning effect of isokinetic measurements in healthy subjects, and reliability and comparability of Biodex and Lido dynamometers. Clin Physiol Funct Imaging. 2005;25:75-82.

31. Sole G, Hamrén J, Milosavljevic S, Nicholson H, Sullivan SJ. Test-retest reliability of isokinetic knee extension and flexion. Arch Phys Med Rehabil. 2007:88:626-31.

\section{Submit your next manuscript to BioMed Central and we will help you at every step:}

- We accept pre-submission inquiries

- Our selector tool helps you to find the most relevant journal

- We provide round the clock customer support

- Convenient online submission

- Thorough peer review

- Inclusion in PubMed and all major indexing services

- Maximum visibility for your research

Submit your manuscript at www.biomedcentral.com/submit
Biomed Central 